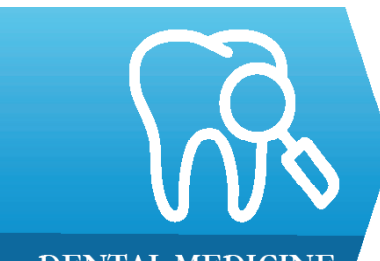

DENTAL MEDICINE

1) Department Implantology, Removable Restorations, Dental Medical Faculty, Grigore T. Popa University of Medicine and Pharmacy, Iasi, Romania

2) Department of Oral Surgery, Dental Medical Faculty, Grigore T. Popa University of Medicine and Pharmacy, Iasi, Romania

\section{Esthetic aspects in implant-prosthetic rehabilitation}

Norina Forna ${ }^{1}$, Doriana Agop-Forna ${ }^{2}$

\begin{abstract}
The esthetic component is critical for the successful outcome and patients' satisfaction regarding the implant-prosthetic therapy. The esthetic outcome success depends mostly on the optimization of the algorithms specific to the pro-implant and implant stage as well as to the designing and technological execution of the future prosthetic restoration. A proper planning of optimal facial esthetics must involve a multidisciplinary approach with inclusion of periodontists, orthodontists, oral surgeons and implantology specialists. The dental practitioner must consider various factors that influence the esthetic outcome (tooth position, root position of the adjacent teeth, biotype of the periodontium, tooth shape, smile line, implant site anatomy, implant positioning). Also, some factors (anatomical limits of the implant site, periodontal status, occlusal parameters), which can alter the final esthetic result, must be assessed prior to planning the esthetic parameters of the future prosthetic restoration. The esthetic outcome can be improved by using new digital technologies based on software applications for assessment of clinical and biological indices of the prosthetic field, virtual planning of implants positioning and design projection of future prosthetic restoration.
\end{abstract}

Keywords: edentation, implants, esthetics

\section{Introduction}

The partial edentation is often associated with complications related to occlusion, soft tissues, bone tissues, muscular components, articular components [1]. The esthetic issue is an important concern of the dental practitioners, since achieving esthetics in the implant-prosthetic therapy is significantly more difficult than with teeth-supported restorations [2]. The implant-supported restoration must harmonize into the frame of the smile, face and the individual [2].

The success of the stomatognathic system functions rehabilitation, including esthetics, depends mostly of the optimization of the algorithms specific to the proprosthetic, pro-implant and prosthetic stage. However, the anatomical limits, occlusal space management, occlusal stability and periodontal status must be considered prior to the planning of the esthetic parameters for the future prosthetic restoration [3].

For each edentulous patient candidate to implants, the dental practitioners' objectives must be multiple. The creation of the most ideal esthetic result is one of the most important objectives of the implant-prosthetic therapy, but the improvement of the oral health and the establishment of the proper occlusal function are other required targets for a successful outcome [4].

An organized and systematic approach during the diagnostic stage will help to address predictably both to the functional and esthetic problems [5]. The management of patients must integrate the knowledges of many fields of dentistry into a comprehensive treatment plan [5]. The modern implantology approach integrates factors like dental implants' designs, materials, and surfaces with clinical and technical management [6,7]. One of the most important ability of the dental practitioner is the understanding of the reactions of the peri-implant soft and bone tissues to dental implants as well as the knowledge of the subjective and objective esthetic criteria [8].

\section{Esthetic criteria}

The esthetic criteria (macroesthetics, miniesthetics, microesthetics) proposed by Sarver \& Ackerman are presented in table I [9]. 
Table I. Esthetic criteria [9].

\begin{tabular}{|c|c|c|}
\hline Macroesthetics & Miniesthetics & Microesthetics \\
\hline Profile & Incisor display & Gingival heights \\
Vertical proportions & Transverse smile & Triangular holes \\
Lip fullness & Smile symmetry & Emergence profiles \\
Chin projection & Crowding & Spacing \\
Nasal projection & Smile arc & Tooth shade \\
Ears & & Tooth space \\
& & Incisor angulations
\end{tabular}

\section{Factors influencing the esthetic outcome}

The most important factors that influence the esthetic outcome of the implant-supported restorations are as follows [2]:

- Patient selection and smile line;

- Tooth position;

- Root position of the adjacent teeth;

- Biotype of the periodontium and tooth shape;

- The bony anatomy of the implant site;

- The position of the implant.

The smile line is highly influenced by lip activity and lip length [10]. The patients with high smile line are more difficult to treat due to the total displaying of the implant-prosthetic restoration and gingival tissues [2]. For this category of patients, the esthetic outcome will depend mostly by the proper maintaining of the peri-implant tissues by supplying proper planning, surgical pro-implant procedures and temporary restoration. The elements that influence the smile designing are as follows [10]:

Tooth components

- Dental midline;

- Incisal lengths;

- Tooth dimensions;

- Zenith points;

- Axial inclinations;

- Interdental contact area (ICA);

- Interdental contact point (ICP);

- Incisal embrasure;

- Symmetry and balance.

Soft tissue components

- Gingival health;

- Gingival levels;

- Interdental embrasure;

- Smile line.

The tooth positions require to be evaluated in apical-coronal, buccal-lingual, and mesio-distal plans, as the tooth position will significantly influence the gingival architecture. For an optimal esthetic result, teeth with poor prognosis must be extracted to prevent a negative influence on hard and soft tissue configuration [2].

The apical-coronal position of the tooth depends on the degree of apically migration of the gingival margin following tooth extraction. The extraction and placement of an implant immediately, is associated to a migration of the gingival margin of approximate $0.2 \mathrm{~mm}$ [11]. As long clinical crowns and pink ceramic may compromise the esthetic outcome (especially for high smile line patients), it is recommended orthodontic extrusion of the teeth considered for extraction [12].

The facial-lingual position is important as the tooth positioned too far facially, will be associated to very thin labial bone and the extraction of these teeth will conduct to significant vertical bone loss and collapse of the gingival architecture [2]. In this clinical situation it must be considered guided bone and soft tissues regeneration procedures prior to implant placement [13].

The mesio-distal position is closely related to the proximal contact and the aspect and volume of interdental papillae should be evaluated. Higher or lower mesiodistal position requires the use of orthodontics therapy, enameloplasty, or composite restorations [2]. For patients with diastemas, the closing of the space with implant restoration will be associated to an non-esthetic black triangle and the absence of interdental papillae.

Root position of the adjacent teeth influence the planning of the dental implants positioning and orientation, as the thin interproximal bone conducts to lateral resorption that will decrease the vertical post-extraction bone height. When the root position of the adjacent teeth is not favorable, orthodontic therapy is required to reposition the adjacent teeth [14].

Biotype of periodontium influences the esthetics of the future implant-prosthetic restoration. The thin periodontium ( $15 \%$ frequency), characterized by soft tissue curtain, scalloped underlying osseous form, is predisposed to dehiscence and fenestrations and has reduced quantity and quality of keratinized mucosa [15]. Often it is associated with recession and inter-root bone resorption, conducting to the soft tissue loss that compromises the esthetic result. For patients with thin biotype the implant body and shoulder must be placed more palatal, with slightly deeper placement, to mask the visibility of titanium and to allow for proper emergence profile [2]. The patients with thick biotype of periodontium ( $85 \%$ frequency) have increased 
quantity and quality of attached keratinized gingiva and more favorable conditions for a proper esthetic outcome [2].

The form of tooth also influences the final esthetic result. In the case of triangular teeth, the loss of interproximal tissue will display wider black triangle than in a situation of square tooth [2]. The dental practitioner must relate the tooth shape to implant restoration shape. The aim is to provide proper support of the gingival tissue without excessive pressure, in relation to the height of the free gingival margin and the distance to contralateral tooth [2]. When the free gingival margin is positioned to apical area, the subgingival contour must be concave to allow the soft tissue to drape more coronally. When the free gingival margin is positioned to the coronal area, the subgingival contour must be fuller to push the soft tissue more apically.

The bone anatomy of the implant site influences the possibility to place the dental implant in an ideal position [16]. In clinical situation with improper bone anatomy of the implant site (height and width), the dental practitioner must perform guided bone regeneration procedure to provide optimum esthetic outcome. A proper planning of the pro-implant surgical procedure and the measurements of implant sites parameters must be performed by using CBCT scans and software applications [17-19].

The analysis of the height and thickness of the facial bone wall and of the height of the alveolar crest in the interproximal areas are especially important to predict the evolution of gingival tissues after implant placement [2].

One study found a direct relation between the risk of soft tissue loss and the distance between osseous crest and free gingival margin [20]. If the vertical distance of the dentogingival complex on the midfacial aspect is $3 \mathrm{~mm}$, the dental practitioner must anticipate a slight apical loss of tissue up to $1 \mathrm{~mm}$ after extraction and immediate implant placement. The distance from the free gingival margin to the osseous crest prior to extraction represents a diagnostic predictor of the final position of the free gingival margin [20].

The height of the bony crest in the interproximal area predicts the presence or absence of peri-implant papillae. One study showed that the height of peri-implant papillae in single tooth gaps is independent from the proximal bone level next to the implant but is dependent on the interproximal bone height of the adjacent teeth [21]. If the distance from the tip of the papilla to the interproximal bone crest of the adjacent tooth is $5 \mathrm{~mm}$ or less, the interproximal tissues will be maintained following implant placement and restoration. However, in the clinical cases with a distance greater than $5 \mathrm{~mm}$, there is an increased probability that the papilla will not be maintained after implant placement [21].

The implant placement influences significantly the esthetic result. The implants placement must be performed to satisfy the parameters related to teeth contour and to allow the maintenance of bone and gingival tissue architecture [2]. Immediate implant placement after extraction can reduce the amount of ridge width reduction. It is recommended orthodontic eruption of the tooth planned for extraction, in clinical cases with severe bone defects [22].

The most important for dental implants placement is apical-coronal positioning, as errors in apical-coronal implant placement will conduct to negative esthetic and biomechanical implications [2]. A large discrepancy between the bone level at the proposed implant site and the level at the adjacent teeth. represents a risk to both periodontal and peri-implant tissue health [2]. Guided bone regeneration procedures must be performed prior to implant placement. A low discrepancy between the occlusal surface of the implant and the tip of the bony septa proximal to the adjacent teeth is favorable for a pleasing esthetics [2]. The use of the surgical guide will help to obtain appropriate apical-coronal positioning of the implant. If the placement of the dental implant is too coronally the restoration will look short in comparison to the contralateral tooth. If the dental implant is placed too apically, a high amount of bone loss will occur and it will affect both the proximal bone structure and the height of the facial bone wall, leading to unaesthetic soft tissue contours [2].

The mesio-distal placement of the dental implants influences the generation of interproximal papillary support and the osseous crest of the adjacent tooth. Ideally, the dental implant must be placed $1.5 \mathrm{~mm}$ to $2 \mathrm{~mm}$ from an adjacent tooth [2]. The placement of an implant too close to the adjacent tooth conducts to the resorption of the interproximal alveolar crest to the level of the implant, associated with the reduction of the interproximal papilla height [23].

The facio-lingual placement of the dental implants is related to the alveolar crest width. Lower alveolar crest width requires bone augmentation for proper facio-lingual position of the dental implant. Also, in this clinical situation, the measurements of the implant sites parameters must be performed by using CBCT scans and software applications. The planning of implant positioning must consider that the amount of bone available must be minimum $1 \mathrm{~mm}$ greater than the implant diameter on each side. In the clinical cases with the loss of a single anterior tooth, the dental implant must be placed palatal to an imaginary line that outlines the curve of the arch formed by the facial surfaces of the adjacent teeth [2].

The esthetic troubles after errors in implants positioning can be synthesized as follows [2]:

- If the implant is placed too shallowly, a ridge lap may be required on the facial, which may compromise soft tissue health;

- If the implant is placed too deep, instrumentation problems will appear and the compromise of the adjacent teeth health;

- If the implant is placed too palatally, it will result in biomechanical compromises;

- If the implants are placed too close together, it will compromise the contours of the future implant-prosthetics 
restoration as well as the loss of papilla and flattening of tissue;

- If the implants are placed too facially, it will result in the thinning of bone, tissue recession and loss of interproximal papilla.

In conclusion, the ideal placement of the dental implants for optimum esthetic results should be at 3-4 $\mathrm{mm}$ apically to the free gingival margin, and in the case of multiple implants, these should be inserted with a distance at least $3 \mathrm{~mm}$ between them, considering the size of the anticipated teeth [2].

\section{Factors related to peri-implant bone loss}

One of the most important factors that negatively influences the esthetics is the small changes in crestal bone height following implant restoration. The factors that accelerate the bone loss around dental implants are as follows [2]:

- Surgical trauma [24];

- Stress concentration at the coronal region of the implant when implants are placed into function [24];

- Bacterial leakage due to configuration and position of the implant-abutment microgap [25];

- Localized inflammation at the implant-abutment interface [26];

- Biological width theory [27];

- Repeated screwing and unscrewing of the abutment [28];

- Periimplantitis [29];

- Implant neck geometry [30].

\section{Possibilities to minimize peri-implant bone}

loss

The possibilities to minimize the peri-implant bone loss are [2]:

- Altering the implant neck design;

- Microthreads at the coronal aspect of the implant;

- Altering implant surface characteristics;

- Altering the diameter of implant;

- Use of one-piece implants;

- Placing implants in relation to the alveolar crest.

The role of the implant neck design on marginal bone loss levels is controversial [30]. However, one study found that implants with rough neck design and microthreads, placed in anterior maxillary area, have limited marginal bone loss and $100 \%$ survival rate after 5 years [31].

The addition of microthreads at the coronal aspect of the implant has the role to distribute the peri-implant forces under functional load and to increase the bone-to-implant contact (BIC). Two five-years studies demonstrated that implants with microthreads have lower marginal bone loss than average values reported for original machined surface external hex implants $[31,32]$.

The implant surface features can influence the marginal bone loss. Various techniques (acid etching, oxidizing, anodization, sandblasting, laser) are used to increase the implant surfaces roughness and thus to improve implants osseointegration and bone-to-implant contact $[34,35]$.

The role of the implants diameters in minimizing marginal bone loss is controversial. The implants producers claim that wide diameter implants exhibit less horizontal bone resorption than regular diameter implants. One 4-7 years study found that ultra-wide diameter implants for immediate molar replacement demonstrate little bone loss and stable soft tissue conditions [36].

The one-piece implants are placed in a one-stage surgery, avoiding further intervention on the soft and bone tissues, eliminating the implant abutment microgap and thus reducing the marginal bone loss [37]. One 10-year study found that one-piece narrow-diameter implants can predictably restore missing maxillary lateral incisors and mandibular incisors with limited marginal bone loss [38]. However new studies are required to confirm the advantage of one-piece implants over two-pieces implants regarding the ability to minimize marginal bone loss.

The insertion depths of the dental implants can influence the marginal bone loss. Higher marginal bone loss was found for the dental implant systems where the implant abutment interface is placed below the gingival margin $[39,40]$.

The platform switching implant systems (implants with implant abutment junction positioned away from the outer edge of the implant and adjacent bone)- It was found that platform switching implants present lower crestal bone loss compared to the nonplatform-switched and the geometry of the implant abutment connection has limited importance in the preservation of peri-implant bone and soft tissues [41-43].

\section{Esthetic factors in multiple implants- supported restorations}

The positioning and the orientation of implants in multiple edentulous spaces must follow the proper diagnosis and treatment planning. In these clinical situations diagnostic wax-up and classic or digital fabrication of the surgical guide are required to avoid wrong position that will alter both the esthetic and functional results [2].

The dental practitioner must consider also the most relevant factors that influence the esthetic outcome [2]:

- Ridge width

- Soft tissue volume

- Smile line

In cases with insufficient width of the alveolar crest, guided bone regeneration procedures are required to create conditions for optimal esthetic outcome. In anterior areas with optimal bone and soft tissues thickness, it is recommended the sculpting of the tissue with ovate pontics to produce an illusion of interproximal papilla 
[44]. The root submergence technique was suggested to maintain the natural attachment apparatus of the tooth in the pontic site, to allows for complete preservation of the alveolar bone frame and to create satisfactory esthetic result in adjacent multiple tooth-replacement cases [45]. In clinical situations where soft tissue thickness is suboptimal for ovate pontics, alternative pontic designs must be considered. A novel pontic design was proposed by scoring of the master casts in the pontic area to allow compression of the soft tissue and gradually changing of the implant sites topography under pressure. The controlled pressure enhances the interdental papilla and creates the illusion of pontics emerging from the soft tissue, to supply a natural-looking effect [46]. This stage is followed by temporary restorations to test the soft tissue response, to obtain optimum soft tissue health that will allow the definitive implant-prosthetic restoration with optimal esthetic results.

\section{Possibilities to improve esthetic outcome} using digital applications

The esthetic results will significantly improve in the implant-prosthetic therapy in Romania, as digital dental technology has been successfully implemented in current dentistry practice [47]. Digital systems that can be used to optimize the planning of the alveolar augmentation are as follows: Implant 3D (Universe, USA), NobleGuide (Nobel Biocare, USA), Digital Smile Design (DSD), SimPlant (Materialise Dental), Virtual Implant Placement (BioHorizons, Anglia), ImplantMaster (iDent, USA), Implant 3D (Media Lab, Italia), EasyGuide (Keystone Dental). Software applications can improve the analysis of clinical and biological indices of the prosthetic field at baseline and following the pro-implant stage $[48,49]$. Digital Smile Design offers the possibility of increasing the level of satisfaction of the patient with the complex prosthetic treatment, due to correlation with the dynamic movement and the connections between the teeth, gums, lips and smile [50]. Also, new CAD-CAM technologies allow the manufacturing of aesthetic crowns or fixed prosthetic restorations from glass-ceramics, zirconia, nano-ceramic resins and hybrid ceramic materials [51].

Some considerations regarding the therapeutic approach for an optimal esthetic outcome in the anterior implant-prosthetic rehabilitation are presented in figures 1-5 (maxillary anterior edentation treated by implantprosthetic therapy).

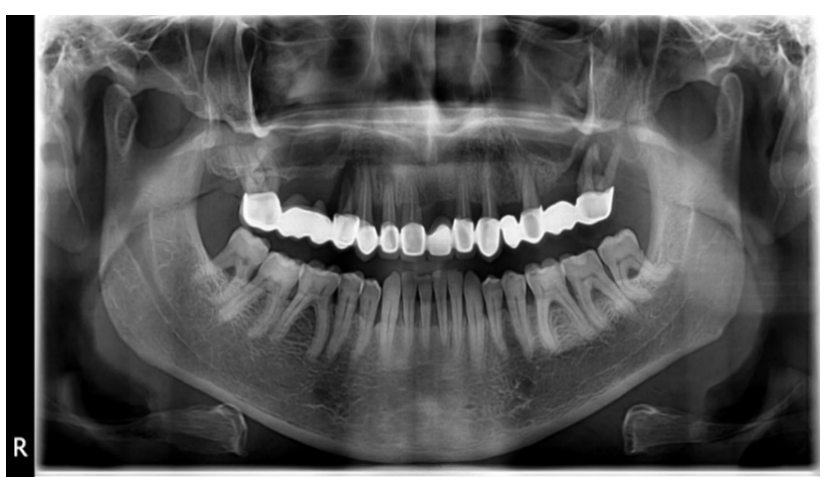

Figure 1. Radiograph shows moderate bone loss in anterior maxillary area. The dental practitioner must consider the use of long contact area to compensate the predicted loss of tissue [2].

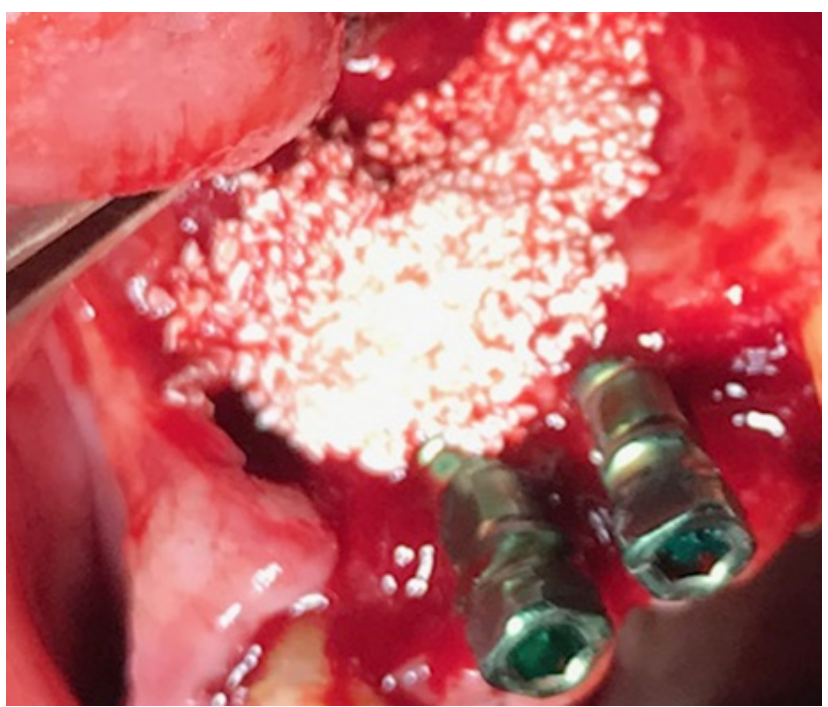

Figure 2. Graft procedures simultaneous with implant placement to ensure proper dimensional parameters of the implant sites.

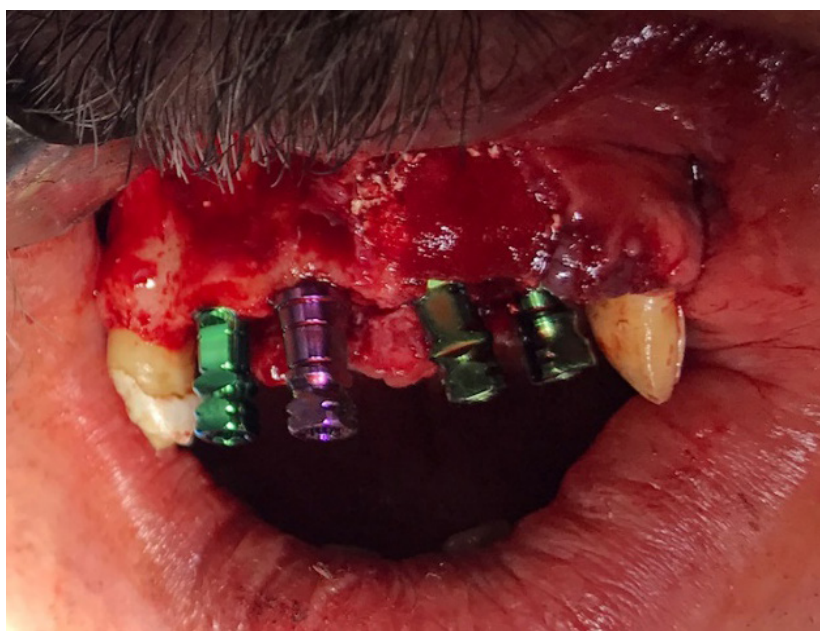

Figure 3. Proper implant placement to ensure optimal esthetic results. 


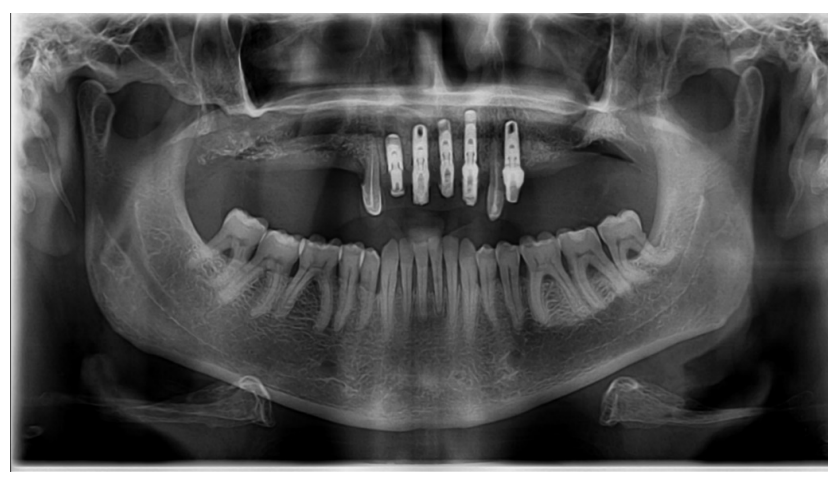

Figure 4. Postimplant radiographic aspects.

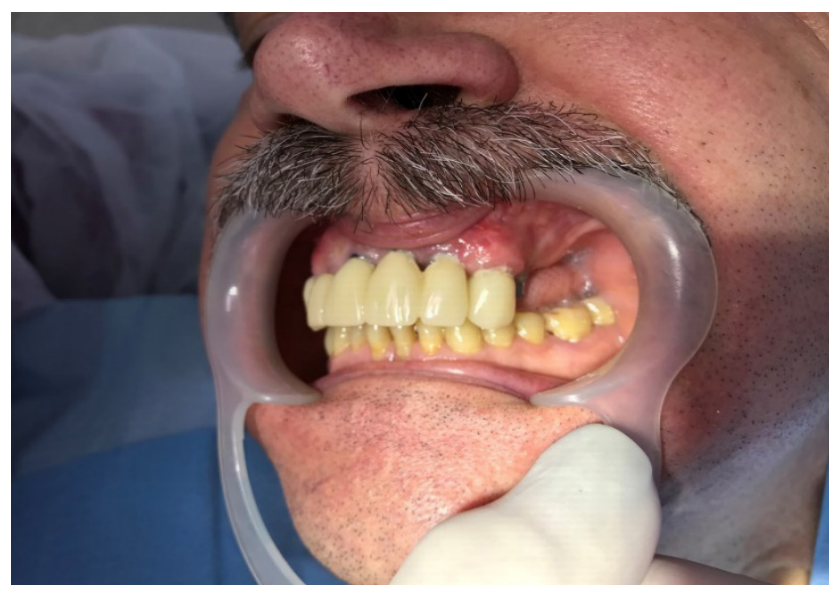

Figure 5. Provisional restoration.

\section{Conclusions}

Satisfactory esthetic outcome is challenging in the implant-supported restorations of anterior teeth. Various factors must be taken in the planning of the esthetic results (tooth position, root position of the adjacent teeth, biotype of the periodontium, tooth shape, smile line, implant site anatomy, implant positioning). The maximization of the esthetic outcome depends mostly on the optimization of the algorithms specific to the pro-prosthetic, proimplant and prosthetic stage. The esthetic outcome can be improved by using new digital technologies based on software applications for assessment of clinical and biological indices of the prosthetic field, virtual planning of implants positioning and design projection of future prosthetic restoration. Despite the improvement of implant design, surfaces characteristics, and materials bioactivity, dental practitioners must focus not only on dental implants osseointegration but also to the achievement of implant-supported restorations that are in harmony with peri-implant soft tissues and bone. The anatomical limits, occlusal space management, occlusal stability and periodontal status must also be considered prior to plan the esthetic parameters of the future prosthetic restoration.

\section{References}

1. Forna N. Tratat de Protetică Dentară (Treatise of Dental Prosthetics). București: Editura Enciclopedică; 2011: pp. 2.

2. Jivraj S, Reshad M. Esthetic implant dentistry: diagnosis and treatment planning. In: Frost RJ (ed) Oral and Maxillofacial Surgery. Elsevier; 2018: pp. 391-409.

3. Reshad M, Jivraj S. The influence of posterior occlusion when restoring anterior teeth. J Calif Dent Assoc. 2008;36:567574.

4. Jivraj S, Chee W. Treatment planning of implants in the aesthetic zone. Br Dent J. 2006;201:77-89.

5. Jivraj S. Treatment planning: An art or a science? J Calif Dent Assoc. 2008;36:563-564.

6. Mankoo T. Maintenance of interdental papillae in the esthetic zone using multiple immediate adjacent plants to restore failing teeth-a report of ten cases at 2 to 7 years follow-up. Eur J Esthet Dent 2008; 3(4):304-322.

7. Sullivan RM. Perspective on esthetics in implant dentistry. Compend Contin Educ Dent. 2001;22:685-692; quiz 694.

8. Magne P, Belser U. Natural oral esthetics. In: Bonded porcelain restorations in the anterior dentition. A biomimetic approach. Chicago: Quintessence; 2002: pp. 57-99.

9. Sarver DM, Ackerman MB. Dynamic smile visualization and quantification: part 1. Evolution of the concept and dynamic records for smile capture. Am J Orthod Dentofacial Orthop. 2003;124:4-12.

10. Bhuvaneswaran M. Principles of smile design. J Conserv Dent. 2010;13:225-232.

11. Khzam N, Mattheos N, Roberts D, Bruce WL, Ivanovski S. Immediate placement and restoration of dental implants in the esthetic region: clinical case series. J Esthet Restor Dent. 2014;26:332-344.

12. Kois JC. Predictable single tooth peri-implant esthetics: five diagnostic keys. Compend Contin Educ Dent. 2004;25:895896, 898, 900 passim; quiz 906-7.

13. Urban IA, Nagursky H, Lozada JL, Nagy K. Horizontal ridge augmentation with a collagen membrane and a combination of particulated autogenous bone and anorganic bovine bonederived mineral: a prospective case series in 25 patients. Int J Periodontics Restorative Dent. 2013;33:299-307.

14. Tarnow DP, Cho SC, Wallace SS. The effect of interimplant distance on the height of inter-implant bone crest. J Periodontol. 2000;71:546-549.

15. Becker W, Ochsenbein C, Tibbetts L, Becker BE. Alveolar bone anatomic profiles as measured from dry skulls. Clinical ramifications. J Clin Periodontol. 1997;24:727-731.

16. Martin WC, Pollini A, Morton D. The influence of restorative procedures on esthetic outcomes in implant dentistry: a systematic review. Int J Oral Maxillofac Implants. 2014;29 Suppl:142-154.

17. Scherer MD. Presurgical implant-site assessment and restoratively driven digital planning. Dent Clin North Am. 2014;58:561-595.

18. Ganz SD. Cone beam computed tomography-assisted treatment planning concepts. Dent Clin North Am. 2011;55:515-536, viii. 
19. Vercruyssen M, Laleman I, Jacobs R, Quirynen M. Computer-supported implant planning and guided surgery: a narrative review. Clin Oral Implants Res. 2015;26 Suppl 11:69-76.

20. Kois JC, Kan JY. Predictable per-implant gingival esthetics. Surgical and prosthodontic rationales. Pract Proced Aesthet Dent. 2001;13:691-698; quiz 700, 721-2.

21. Nisapakultorn K, Suphanantachat S, Silkosessak O, Rattanamongkolgul S. Factors affecting soft tissue level around anterior maxillary single-tooth implants. Clin Oral Implants Res. 2010;21:662-670.

22. Chen ST, Buser D. Esthetic outcomes following immediate and early implant placement in the anterior maxilla--a systematic review. Int J Oral Maxillofac Implants. 2014;29 Suppl:186-215.

23. Thilander B, Odman J, Jemt T. Single implants in the upper incisor region and their relationship to the adjacent teeth. An 8-year follow-up study. Clin Oral Implants Res 1999;10:346355.

24. Capelli M. Surgical, biologic and implant-related factors affecting bone remodeling around implants. Eur $\mathrm{J}$ Esthet Dent. 2013;8:279-313.

25. Albrektsson T, Zarb G, Worthington P, Eriksson AR. The long-term efficacy of currently used dental implants: a review and proposed criteria for success. Int J Oral Maxillofac Implants. 1986;1:11-25.

26. Pilliar RM, Deporter DA, Watson PA, Valiquette N. Dental implant design. Effect on bone remodeling. J Biomed Mater Res. 1991;25:467-483.

27. Cappiello M, Luongo R, Di Iorio D, Bugea C, Cocchetto R, Celletti R. Evaluation of peri-implant bone loss around platform-switched implants. Int J Periodontics Restorative Dent. 2008;28:347-355.

28. Canullo L, Pellegrini G, Allievi C, Trombelli L, Annibali S, Dellavia C. Soft tissues around long-term platform switching implant restorations: a histological human evaluation. Preliminary results. J Clin Periodontol. 2011;38:86-94.

29. Al-Aali KA, ArRejaie AS, Alrahlah A, AlFawaz YF, Abduljabbar T, Vohra F. Clinical and radiographic periimplant health status around narrow diameter implantsupported single and splinted crowns. Clin Implant Dent Relat Res. 2019;21:386-390.

30. Bateli M, Att W, Strub JR. Implant neck configurations for preservation of marginal bone level: a systematic review. Int J Oral Maxillofac Implants. 2011;26:290-303.

31. Calvo-Guirado JL, López-López PJ, Pérez-Albacete Martínez C, Javed F, Granero-Marín JM, et al. Peri-implant bone loss clinical and radiographic evaluation around rough neck and microthread implants: a 5-year study. Clin Oral Implants Res. 2018;29:635-643.

32. Calvo-Guirado JL, Gómez-Moreno G, Aguilar-Salvatierra A, Guardia J, Delgado-Ruiz RA, Romanos GE. Marginal bone loss evaluation around immediate non-occlusal microthreaded implants placed in fresh extraction sockets in the maxilla: a 3-year study. Clin Oral Implants Res. 2015;26:761-767.
33. Palmer RM, Palmer PJ, Smith BJ. A 5-year prospective study of Astra single tooth implants, Clin Oral Implants Res. 2000;11:179-182.

34. Albrektsson T, Wennerberg A. Oral implant surfaces: Part 1. Review focusing on topographic and chemical properties of different surfaces and in vivo responses to them. J Dent Res. 2006;85:496-500.

35. Rupp F, Liang L, Geis-Gerstorfer J, Scheideler L, Hüttig F. Surface characteristics of dental implants: a review. Dent Mater. 2018;34(1):40-57.

36. Hattingh A, Hommez G, De Bruyn H, Huyghe M, Vandeweghe S. A prospective study on ultra-wide diameter dental implants for immediate molar replacement. Clin Implant Dent Relat Res. 2018;20:1009-1015.

37. Jones AA, Cochran DL. Consequences of implant design. Dent Clin North Am. 2006;50:339-360, v.

38. Kadkhodazadeh M, Safi Y, Moeintaghavi A, Amid R, Baghani MT, Shidfar S. Marginal Bone Loss Around OnePiece Implants: A 10-Year Radiological and Clinical Followup Evaluation. Implant Dent. 2019;28:237-243.

39. Pellicer-Chover H, Peñarrocha-Diago $M$, Peñarrocha-Oltra D, Gomar-Vercher S, Agustín-Panadero R, PeñarrochaDiago M. Impact of crestal and subcrestal implant placement in peri-implant bone: A prospective comparative study. Med Oral Patol Oral Cir Bucal. 2016;21:e103-e110.

40. Al Amri MD, Al-Johany SS, Al Baker AM, Al Rifaiy MQ, Abduljabbar TS, Al-Kheraif AA. Soft tissue changes and crestal bone loss around platform-switched implants placed at crestal and subcrestal levels: 36-month results from a prospective split-mouth clinical trial. Clin Oral Implants Res. 2017; 28:1342-1347.

41. Nayak R, Devanna R, Dharamsi AM, Shetty J, Mokashi R, Malhotra S. Crestal Bone Loss around Dental Implants: Platform Switching vs Platform Matching-A Retrospective Study. J Contemp Dent Pract 2018;19:574-578.

42. Alonso-González R, Aloy-Prósper A, Peñarrocha-Oltra D, Peñarrocha-Diago MA, Peñarrocha-Diago M. Marginal bone loss in relation to platform switching implant insertion depth: An update. J Clin Exp Dent. 2012;4:173-179.

43. Atieh MA, Ibrahim HM, Atieh AH. Platform switching for marginal bone preservation around dental implants: a systematic review and meta-analysis. J Periodontol. 2010;81:1350-1366

44. Salama MA, Salama H, Garber DA: Guidelines for aesthetic restorative options and implant site enhancement. Pract Proced Aesthet Dent 2002; 14:125-130.

45. Salama M, Ishikawa T, Salama H, Funato A, Garber D. Advantages of the root submergence technique for pontic site development in esthetic implant therapy. Int J Periodontics Restorative Dent. 2007;27:521-527.

46. Kim TH, Cascione D, Knezevic A. Simulated tissue using a unique pontic design: a clinical report. J Prosthet Dent. 2009;102:205-210.

47. Meleșcanu-Imre M, Purcarea VL, Pantea M, Țâncu AMC. Study on application of digital technologies in dental practice. Romanian Journal of Oral Rehabilitation 2019; $11: 35-42$. 
48. Forna N, Feier RD, Dascalu CG. Study regarding the possibilities to use the application of computerized score in the patient evaluation. Romanian Journal of Oral Rehabilitation 2018;10:113-118.

49. Forna D, Feier R, Topoliceanu C, Forna N, Popescu E. Study regarding the possibilities to use the application Prodent in the pro-prosthetic stage. Romanian Journal of Oral Rehabilitation 2017;9:97-100.
50. Luca E, Iordache C, Țănculescu O, Surlari Z, Virvescu D, Checheriță L, Ciocan-Pendefunda A, Beldiman MA. Aspects of aesthetic rehabilitation using digital smile design. Romanian Journal of Oral Rehabilitation 2019;11:119-123.

51. Rotar R, Jivanescu A, Pricop C, Toser I, Todor R, Gruia C, Fabricky M. CAD/CAM chair-side material options for anterior crowns. Romanian Journal of Oral Rehabilitation 2019; $11: 33-38$. 